University of Nebraska - Lincoln

DigitalCommons@University of Nebraska - Lincoln

Mechanical \& Materials Engineering Faculty

Publications

Mechanical \& Materials Engineering,

Department of

1997

\title{
Part Form Errors Predicted from Machine Tool Performance Measurements
}

R. G. Wilhelm

N. Srinivasan

F. Farabaugh

R. Hocken

Follow this and additional works at: https://digitalcommons.unl.edu/mechengfacpub

Part of the Mechanics of Materials Commons, Nanoscience and Nanotechnology Commons, Other Engineering Science and Materials Commons, and the Other Mechanical Engineering Commons

This Article is brought to you for free and open access by the Mechanical \& Materials Engineering, Department of at DigitalCommons@University of Nebraska - Lincoln. It has been accepted for inclusion in Mechanical \& Materials Engineering Faculty Publications by an authorized administrator of DigitalCommons@University of Nebraska Lincoln. 


\title{
Part Form Errors Predicted from Machine Tool Performance Measurements
}

\author{
R. G. Wilhelm, N. Srinivasan, F. Farabaugh, and R. Hocken \\ Precision Engineering Laboratory, University of North Carolina at Charlotte, USA
}

\begin{abstract}
Machine tool performance testing, as defined by IS0 230 and ANSI B5.54 has been successfully used to maintain and improve the accuracy and repeatability of production-level machine tools. In this study, a controlled series of experiments have been used to test the efficacy of these performance tests in the prediction of part form errors. Results are shown for flatness, squareness, position, and profile tolerances. The experimental results suggest that standard machine tool performance tests can also be used to predict the "best-case" tolerances that can be achieved for particular part features.
\end{abstract}

Keywords: machining, metrology, tolerancing

\section{Introduction}

Machine tool performance tests were initially created [16] to qualify newly purchased machines according to a series of component measurements. Modern testing standards [1,9], both ANSI and ISO, characterize the ability of the machine to accurately and repeatably position the cutting tool relative to the work piece. These tests are often used to qualify, maintain, and improve production-level machine tools. The experimental results of this paper show that these standard tests can also be used to predict the "best-case" tolerances that can be achieved for a particular part feature on a particular machine tool.

In previous work, machine tool errors [13] and thermal behavior [3] have been studied and characterized in considerable detail. Many methods have been developed $[4,6,8,12,14$, $17,18,23]$ for the modeling and compensation of both quasistatic and dynamic errors. Some effort has been made to characterize the statistical behavior of machine tool errors [5]. Correlation has also been established for turned workpieces and spindle behavior [11,15,21]. 
The work reported here goes further by relating the measured behavior of the machine tool to variations found in prismatic part features that have been cut on the machine tool.

The part features studied in these experiments correspond to the geometric tolerance features defined by ANSI and ISO [2,10]. The machine tool variations correspond to standard tests [1,9] available for environmental effects, displacement accuracy, geometric accuracy, and volumetric performance.

Experiments were carefully planned and executed to isolate the effects of particular machine tool errors. The machining and metrology conditions were very tightly controlledbeyond those found in many production facilities. All of the error relationships are experimentally determined and experiments would have to be repeated for any other class of machine to be characterized.

\section{Experimental Approach}

A three-axis horizontal spindle machining center was used for all of the cutting experiments. Prior to any machining operations, the machining center was tested according to the B5.54 machine tool testing standard. As illustrated in Table 1, the machine had errors of a scale that would be expected in a production machine.

\begin{tabular}{|c|c|c|}
\hline & Geometric Error & Measured Value \\
\hline Linear Displacement & $\begin{array}{l}\text { X-Axis } \\
\text { Y-Axis } \\
\text { Z-Axis }\end{array}$ & $\begin{array}{r}9 \text { micrometers } \\
10 \text { micrometers } \\
26 \text { micrometers }\end{array}$ \\
\hline Angular Errors & $\begin{array}{l}\text { Roll of } X \\
\text { Pitch of } X \\
\text { Yaw of } X \\
\text { Roll of } Y \\
\text { Pitch of } Y \\
\text { Yaw of } Y \\
\text { Roll of } Z \\
\text { Pitch of } Z \\
\text { Yaw of } Z\end{array}$ & $\begin{array}{l}8 \text { arc seconds } \\
8.5 \text { arc seconds } \\
7 \text { arc seconds } \\
7 \text { arc seconds } \\
2 \text { arc seconds } \\
5.5 \text { arc seconds } \\
\quad- \\
32 \text { arc seconds } \\
4.5 \text { arc seconds }\end{array}$ \\
\hline Straightness & $\begin{array}{l}\text { Y-Straightness of } X \\
\text { Z-Straightness of } X \\
\text { X-Straightness of } Y \\
\text { Z-Straightness of } Y \\
\text { X-Straightness of } Z \\
\text { Y-Straightness of } Z\end{array}$ & $\begin{array}{r}18 \text { micrometers } \\
3 \text { micrometers } \\
9 \text { micrometers } \\
2 \text { micrometers } \\
10 \text { micrometers } \\
32 \text { micrometers }\end{array}$ \\
\hline Squareness & $\begin{array}{l}\text { X, Y Squareness } \\
X, Z \text { Squareness } \\
\text { Y, Z Squareness }\end{array}$ & $\begin{array}{l}8 \text { micrometers per } 200 \mathrm{~mm} \\
\quad- \\
\quad-\end{array}$ \\
\hline
\end{tabular}

The machine errors were then compared to errors measured on test parts that were machined on a commercial machining center. While several different test parts were used for the experiments, a typical test part is shown in Figure 1. Initial parts were cut in 6061 rolled 
aluminum. Later experiments were also conducted using 7075 cast aluminum and cast iron.

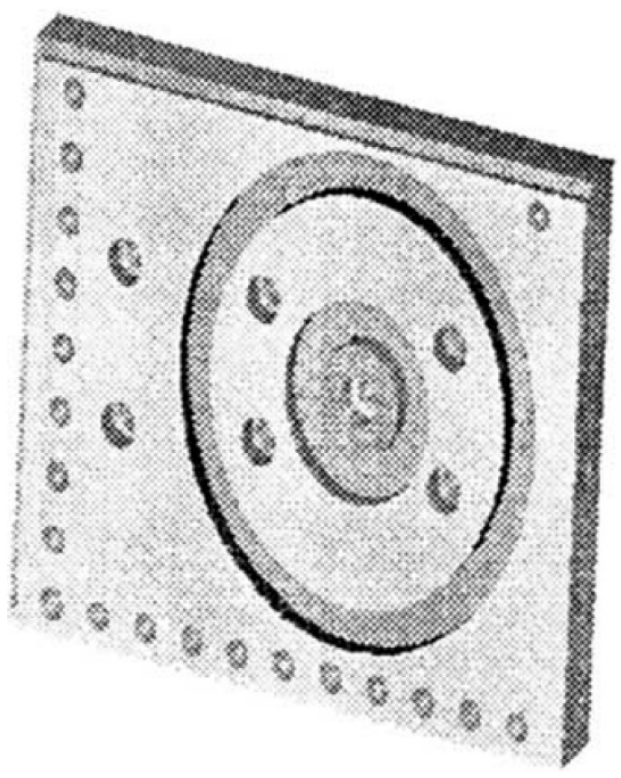

Figure 1. Test Part II

The process plans for the machining experiments were chosen to reduce effects that would be attributed to long machining time, heavy cutting forces, and residual stress. In Test Part II, large volumes of material corresponding to the largest contour were removed before final facing and boring were done. Fine finishing cuts at depths of $1 \mathrm{~mm}$ or less were used. Since the parts were cut on a horizontal machining center, a steel angle plate was used to position each workpiece. A three-point bolting scheme was used to minimize contact between the steel and aluminum while approximating a kinematic mount and avoiding unnecessary warping and distortion. Using uniform bolt torques, the fixturing scheme provided repeatable fixtured poses for each part. All machining operations were completed in a machining laboratory with an ambient temperature of approximately $25^{\circ} \mathrm{C}$. For all machining experiments, the ambient temperature varied by less than $1^{\circ} \mathrm{C}$. Coolant was sprayed over the spindle and part throughout the machining process. Several different measurements of the coolant temperature indicated a variation of less than $1^{\circ} \mathrm{C}$ during the machining operations. Thermal stability errors were avoided by exercising the machine before each workpiece cutting cycle for a set time period determined from previous machining experiments [19]. Part temperature was also monitored during each workpiece cutting cycle. New tool inserts were used for each workpiece cutting cycle. Feed rates and cutting speeds were chosen conservatively. An initial factorial experiment was used to demonstrate that the chosen feeds, speeds, and thermal conditions did not have a significant influence on the final part errors. Manual tool setting techniques with measurement 
and inspection of each insert offset were used to set the inserts in each tool assembly. Further details of the experimental conditions are presented in $[7,19,22]$.

The precision metrology laboratory at UNC Charlotte was used for all part measurements. The lab was temperature controlled to $20^{\circ} \mathrm{C}$ with environmental control of relative humidity and barometric pressure. A coordinate measuring machine (CMM) was used to measure the form errors on the parts. This software error-corrected machine, accurate to about 3 micrometers, was equipped with a PH9 head, allowing rotation about two axes, and a TP2-5W touch trigger probe for data acquisition. Prior to each measurement cycle the ruby stylus and shaft were calibrated using a precision $19.05 \mathrm{~mm}$ sphere with sphericity within approximately one micrometer. Significant efforts were made to clean the parts after machining, as this proved to be the largest source of variation in the metrology process. Additional details are provided in $[7,19,22]$.

Flatness was studied by considering the angular errors of the machine that could influence the position and orientation of a tool during face milling. From the roll and pitch errors of the $\mathrm{X}$ axis and the $300 \mathrm{~mm}$ length of the test part, worst case flatness errors due to machine performance were estimated to be 15 micrometers. This value was then compared to flatness measurements obtained from machined test parts.

Squareness was studied by directly comparing machine squareness measurements to squareness of part features. Machine tool squareness was measured with an indicator in the spindle and a moving square on the machine tool table. The mechanical square was placed nominally in the same position in the machining envelope as the test parts that were machined. Part squareness was estimated using a very dense sampling pattern (more than 100 points) on the two sides of a step feature.

Position was studied by comparing linear displacement errors of the machine with relative errors between centers of holes in a hole pattern on the test part. The linear displacement accuracy of the $X$ and $Y$ machine axes was measured every 25 millimeters at nominally the same locations as the hole centers of drilled and bored holes of the test part. Repeated measurements in the forward and reverse direction were made and then used to calculate both a sample mean and sample standard deviation for linear displacement accuracy at each measurement position. For the test part holes, an origin was established at the left-most and bottom-most hole of the hole pattern and used to measure the distance between the origin and each hole center. Position errors for the hole centers were then compared to the linear displacement accuracy errors of the machine.

Profile was studied by comparing the ball bar results for the machine with form deviations from a large contoured feature in the test part. The contouring performance of the machine tool was characterized by performing a ball bar measurement at the same nominal location, size, and feed rate as the large circular contour of test part II (see Figure 1). The circular feature of the part was measured with 396 points about the circumference of the feature. The sampling pattern included one point per degree of the circle plus nine additional points near each reversal direction for the circular path $\left(0^{\circ}, 90^{\circ}, 180^{\circ}\right.$, and $\left.270^{\circ}\right)$. 


\section{Results}

Flatness and squareness results are shown in Table 2. Considering the accuracy of the $\mathrm{CMM}$, the machine and part errors are essentially the same.

\begin{tabular}{lcc}
\multicolumn{3}{l}{ Table 2. Results for Flatness and Squareness } \\
\hline Feature & Predicted from Machine Errors & Part Error (avg.) \\
\hline Flatness & $15 \mu \mathrm{m}$ & $14.2 \mu \mathrm{m}$ \\
Squareness & $8.3 \mu \mathrm{m}$ & $10.8 \mu \mathrm{m}$ \\
\hline
\end{tabular}

As shown in Figures 2 and 3, the position errors of the test part holes are almost always explained totally by the errors in linear displacement of the machine. The plots show a two standard deviation band for the linear displacement accuracy measurements taken on the $\mathrm{X}$ and $\mathrm{Y}$ axes. The average position errors measured for three test parts are also plotted. For the $\mathrm{X}$ axis, all of the part errors fall within the two standard deviation band of the machine errors. For the $\mathrm{Y}$ axis, one part generated errors outside of the machine errors.

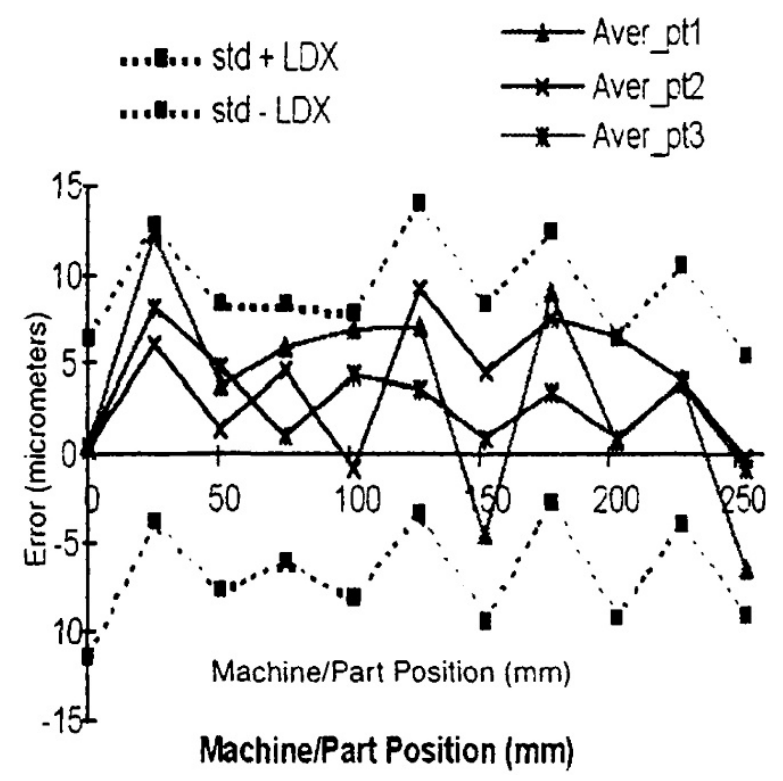

Figure 2. LDX Compared to X Position on Part 


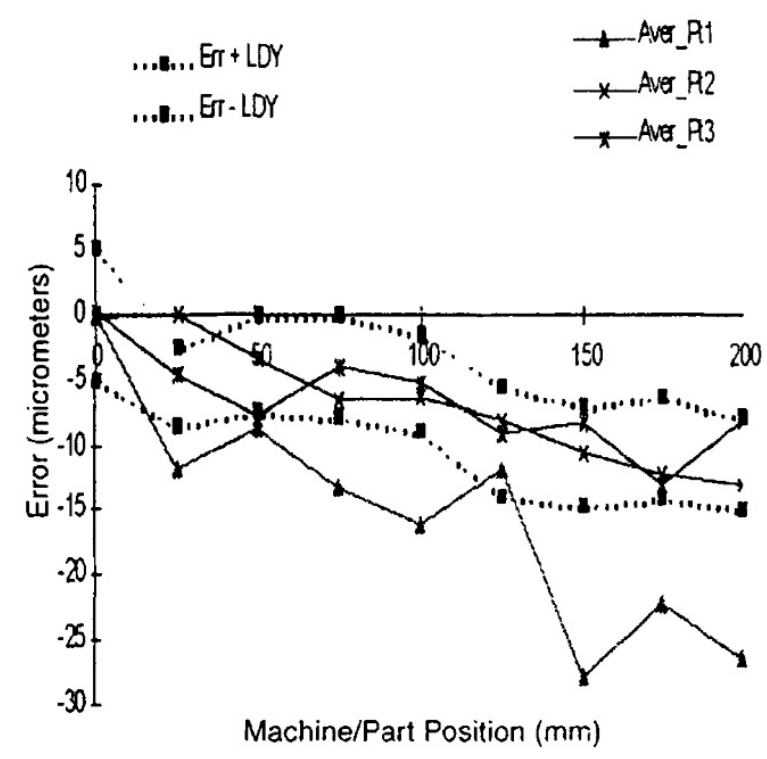

Figure 3. LDY Compared to Y Position on Part

Figure 4 shows the raw data for one test part and for one ball bar measurement. The single large peak at $270^{\circ}$ is due to a motion and velocity discontinuity in the part program. That is, the machine tool was commanded to instantaneously achieve a switch from zero velocity to the feedrate velocity.

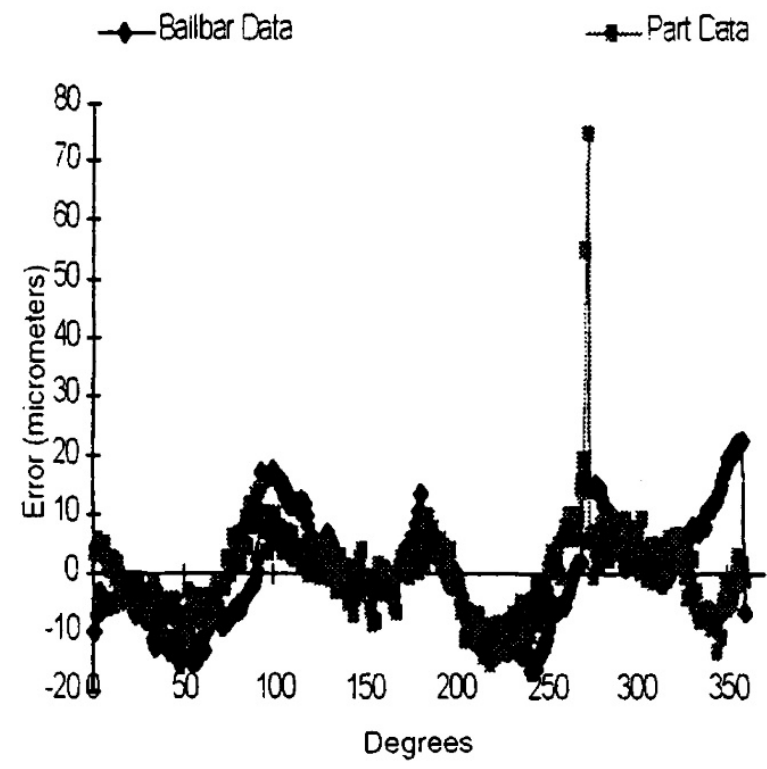

Figure 4. Ball Bar Data Compared to Part Profile 
The raw data suggests that much of the part error can be explained by the contouring error measured with the ball bar test. A Students' T-Test, sliding fit, and a two sigma bandwidth of the ball bar data were evaluated to estimate the statistical significance of this relationship.

For the T-Test analysis, the ball bar data were modified to include an initial constant radius to simulate the perfect contour. Least squares fitting was used to estimate the offsets from center in the $x$ and $y$ direction. The error at each degree was obtained and plotted on a linear plot. Since the ball bar recorded the data at a particular sample rate, averaging and interpolating were done to create a paired analysis with the measured contour data of the part. The contour part data, 396 points, were recorded at degree increments around the perimeter of the part with nine additional points at each reversal point. The nine additional points on the part were averaged into one data point to arrive at the necessary 360 points representing each degree of the contour. The analysis of the 360 points revealed a mean of about zero and a .4451 correlation. The data were further broken into quadrants and analyzed. The mean of differences ranged from -6.431 micrometers to 7.22 micrometers but the differences were normally distributed. Statistical Analysis Software (SAS) was used to determine the correlation of each quadrant: the first .694, the second .732, the third .748, and the fourth .432. The data were rotated as much as 10 degrees to attempt a better correlation, and the results were positive. The fit for the first and fourth quadrants was unchanged but the second and third quadrant fits improved to .76 and .78, respectively.

The second approach involved looking at a two sigma bandwidth of the part contour data and observing whether ball bar data fit inside that bandwidth. The majority of the data for the ball bar plot fell within the bandwidth; however, between each quadrant the data seemed to shift from the upper limit of the bandwidth to the lower limit of the bandwidth. It is unclear what is causing this phenomenon. One possible explanation could be the difference between a loaded tool under cut and the unloaded ball bar performing the measurement.

Further efforts with sliding fits that considered the previous and following data points at each degree position yielded only a one degree rotation from the initial starting position.

While the results here are less conclusive, as much as $80 \%$ of the part error can be explained by the machine tool measurements. Additional systematic errors still must be addressed for this result to be used in application.

\section{Conclusions}

The experimental results of this paper show that standard machine tool performance tests can be used to predict the "best-case" tolerances that can be achieved for a particular part feature on a particular machine tool.

The results are termed "best-case" because the experiments used very conservative machining and metrology practices. Thermal and dynamic process effects were also minimized. Still, the machine performance tests establish a bound that can be used for machine selection and process planning. These results will be especially useful as "normal machining" tolerances continue to decrease [20]. 
If an inventory of machine performance data is maintained, this approach can be used to select machines that are capable of machining part features with particular tolerances. With further software development the standard machine tool performance tests could also provide a very quantitative basis for "design-for-manufacturing" analysis.

\section{Acknowledgments}

This work was funded by the National Center for Manufacturing Sciences as part of the Machine Tool Accuracy Initiative. We thank Chuck Ryan, our program manager, and the directors of Production Equipment and Systems for their strong interest and support. Special thanks also to the National Institute of Standards and Technology which provided the machine tool used in this research. Additional support was provided by the University of North Carolina at Charlotte and the Cameron Applied Research Center. This material is based upon work supported by the National Science Foundation under Grant No. DMI9457168.

This effort was sponsored by the Manufacturing Technology Directorate, Wright Laboratory (WL/MTX), Air Force Materiel Command, USAF, under Cooperative Agreement number F33615-94-2-4423. The U.S. Government is authorized to reproduce and distribute reprints for Governmental purposes notwithstanding any copyright notation herein. The views and conclusions contained herein are those of the authors and should not be inter-

preted as necessarily representing the official policies or endorsements, either expressed or implied, of Wright Laboratory or the U.S. Government.

\section{References}

[1] ANSI/ASME B5.54, Methods for Performance Evaluation of Computer Numerically Controlled Machining Centers, ASME, NY, 1993.

[2] ANSI Y14.5M, Dimensioning and Tolerancing, ASME, NY, 1994.

[3] Bryan, J. B., "International Status of Thermal Error Research," Annals of CIRP, Vol. 39, No. 2, 1990.

[4] Chen, J. S., Yuan, J.X., Ni, J., and Wu, S. M., "Realtime Compensation for Time-variant Volumetric Errors on a Machining Center," Transactions of the ASME, Vol. 115, 1993.

[5] Donmez, M. A., Liu, C. R., Barash, M. M., Mirski, F., "Statistical Analysis of Positioning Error of a CNC Milling Machine," Journal of Manufacturing Systems, Vol. 1, No. 1, 1981.

[6] Donmez, M. A., Blomquist, D. S., Hocken, R. J., Liu, C. R., and Barash, M. M. “A General Methodology for Machine Tool Accuracy Enhancement by Error Compensation," Precision Engineering, Vol. 8, No. 4, 1988.

[7] Farabaugh, F., "Correlating Machine and Part Errors for Improved Machine Tool Accuracy," MS Thesis, The University of North Carolina at Charlotte, 1996.

[8] Hocken, R. J., Simpson, J. A., Borchardt, B., Lazar, J., Reeve, C., and Stein, P., “Three Dimensional Metrology," Annals of CIRP, Vol. 26, No. 2, 1977.

[9] IS0 230, Test Code for Machining Centers, DIS 1991-96.

[10] IS0 1101, Tolerancing of Form, Orientation, Location, and Run-out, ISO, 1983. 
[11] Kakino, Y., Yamamoto, Y., and Ishii, N., "New Measuring Method of Rotating Accuracy of Spindles," Annals of CIRP, Vol. 22, No. 1, 1973.

[12] Kiridena, V. S. B., Ferreira, P. M., "Kinematic Modeling of Quasistatic Errors of Three-Axis Machining Centers," International Journal of Machine Tools and Manufacturing, Vol. 34, No. 1, 1994.

[13] Kline, E. R., Accuracy of Large Machining Centers. Proceedings of the CIRP Conference on Precision Engineering and Manufacturing System, Sept. 1991.

[14] Okushima, K., Kakino, Y., Higashimoto, A., “Compensation of Thermal Displacement by Coordinate System Correction," Annals of CIRP, Vol. 24, No. 2, 1975.

[15] Sawabe, M., and Fujinuma, N. "Influence of Radial Motion on Form Error of Workpiece in Turning," Annals of CIRP, Vol. 27, No. 1, 1978.

[16] Schlesinger, G., revised by K. Koensberger and M. Burdekin, Testing Machine Tools, Pergamon Press, 8th edition, 1978.

[17] Schultschik, R., "The Components of Volumetric Accuracy," Annals of CIRP, Vol. 26, No. 1, 1977.

[18] Soons, J. A., Theuws, F. C., and Schellekens, P. H., "Modeling the Errors of Multi-Axis Machines: A General methodology," Precision Engineering, Vol. 13, No. 1, 1992.

[19] Srinivasan, N., "Correlating Machine Tool Errors with Part Features," MS Thesis, The University of North Carolina at Charlotte, 1995.

[20] N. Taniguchi, "The State of the Art of Nanotechnology for Processing of Ultraprecision and Ultrafine Products," Precision Engineering, Vol. 16, No. 1, 1994.

[21] Vanherck, P., Peters, J., and Siddall, G., "Spindle Error Motion," in Technology of Machine Tools, Vo1. 5: Machine Tool Accuracy, Hocken, R. J., ed., NTIS Doc. No. UCRL-52960-5, Oct. 1980.

[22] Wilhelm, R. G., Srinivasan, N., Farabaugh, F., and Hocken, R., "Prediction of Part Form Errors from Machine Tool Measurements: Experimental Summary," to appear in the Transactions of NAMRI, 1997.

[23] Zhang, G., Ouyang, R., Liu, B., Hocken, R. J., Veale, R., and Donmez, M.A., “A Displacement Method for Machine Geometry Calibration," Annals of CIRP, Vol. 37, No. 2, 1988. 